\title{
1893: año clave del terrorismo en la España de la Restauración
}

\author{
Ángel HerRerín López \\ Prof. Ayudante Doctor. Dpto. H. ${ }^{a}$ Contemporánea. UNED \\ 1893: Specific year of terrorism in the Spanish Restoration
}

\begin{abstract}
RESUMEN
El proceso de Montjuich simbolizó siempre la brutalidad represiva del régimen de la Restauración en España en su lucha contra el anarquismo. Sin embargo, las actuaciones del Estado español tuvieron una primera representación en los atentados acaecidos en Barcelona en el año 1893, principalmente tras la explosión de una bomba en el teatro del Liceo. El presente artículo trata de analizar tanto las acciones de los anarquistas, como las medidas puestas en marcha por las autoridades para la represión de estos acontecimientos.

PALABRAS CLAVES anarquismo, represión, terrorismo, Restauración
\end{abstract}

\section{SUMMARY}

The Montjich process has always symbolized the repressive brutality of the Restoration regime in Spain in the fight against anarchism. However, the actions of the Spanish state had the first representation in the attempts which took place in Barcelona in 1893, mainly after the bomb explosion in the Liceo theatre. The current article tries to analyze the actions of the anarchists as the measures taken by the authorities for the repression of these events.

KEY WORDS

anarchism, repression, terrorism, Restoration 
A finales del siglo XIX y principios del XX el panorama internacional se veía sacudido por las balas, las bombas y los puñales anarquistas. Reyes, emperatrices, presidentes de gobiernos o miembros de la alta burguesía caían como consecuencia de estas acciones, pero también gente de condición más humilde que se encontraban por azar en un café o participaban en una manifestación religiosa ${ }^{1}$.

Los estados afectados por esta actividad violenta intentaban dar una respuesta unitaria y aunar esfuerzos en la lucha antiterrorista. Este fue el objetivo de la Conferencia Internacional Antianarquista de Roma, celebrada entre el 24 de noviembre y el 21 de diciembre de 1898. Asistieron 54 delegados pertenecientes a 21 países europeos. Las posiciones más expeditivas en la lucha contra el terrorismo fueron defendidas por Rusia, Alemania y Austria-Hungría, mientras que en el extremo opuesto, reticente a cualquier recorte de libertades, se encontraba Gran Bretaña. La postura intermedia, defendida por Francia, a la postre sería la aceptada mayoritariamente. Entre las recomendaciones aprobadas en la Conferencia, podemos destacar la elaboración de leyes contra las acciones anarquistas violentas, especialmente con explosivos, pero también contra las asociaciones que tuvieran este fin y contra aquellos que hicieran apología de las mismas. Junto a las penas de prisión para los responsables de las acciones se proponía la prohibición de residencia en determinados lugares y la reproducción de las actas de los procesos, principalmente la declaración de los inculpados, con el fin de evitar la propaganda de las ideas anarquistas que acompañaban sus intervenciones. Al margen de todas estas recomendaciones, se puede decir que en Roma se dio el primer paso para la puesta en marcha de la cooperación internacional en materia de terrorismo en temas como la justicia o la actuación policial. Aunque, como es lógico pensar, la puesta en práctica de todas estas cuestiones, de forma unitaria, no alcanzó el nivel deseado. En parte por las diferencias existentes en el respeto a las libertades de los países participantes, pero también por la difícil colaboración entre los estados europeos en un momento de fuerte enfrentamiento internacional, antesala de la I Guerra Mundial ${ }^{2}$.

Por otra parte, muchas de estas propuestas ya habían sido puestas en práctica por los estados europeos afectados por la violencia anarquista, como era el caso de España. Y aunque en la mayoría de los países de nuestro entorno los atentados tendieron a desaparecer con el cambio de centuria, en nuestro país se alargaron en el tiempo, sin que exista una explicación definitiva sobre las causas que provocaron esta prolongación.

\footnotetext{
1 Véase: AVILÉS, Juan y HERRERÍN Ángel (eds), El nacimiento del terrorismo en Occidente: Anarquía, nihilismo y violencia revolucionaria, Madrid, Siglo XXI, 2008. ÁLVAREZ JUNCO, José, La ideología política del anarquismo español (1868-1910), Madrid, Siglo XXI, 1976. NÚÑEZ FLORENCIO, Rafael, El terrorismo anarquista, 1888-1904, Madrid, Siglo XXI, 1983. GONZÁLEZ CALLEJA, Eduardo, La razón de la fuerza. Orden Público, subversión y violencia política en la España de la Restauración (1875-1917), Madrid, Consejo Superior de Investigaciones Científicas, 1998.

2 AVILÉS, Juan, «Propaganda por el hecho y regicidio en Italia», en AVILÉS, Juan y HERRERÍN Ángel (eds) (2008), pp. 13-17.
} 
Parece evidente que la respuesta del Estado a este tipo de acciones desempeña un papel fundamental en la lucha contra la violencia. Es cierto que el terrorismo es un fenómeno tan sumamente complejo que el análisis de sus causas no se puede circunscribir a un solo aspecto, por lo que es necesario abordarlo desde diferentes perspectivas culturales, sociales, económicas y políticas. Pero no es menos cierto que el terrorismo tiene entre sus principales objetivos el de provocar una reacción desproporcionada del Estado que justifique sus acciones o provoque la reacción popular, cuestiones que alientan su supervivencia. Todas estas circunstancias están presentes en el caso español, por lo que una de las claves para entender la perduración del fenómeno violento en nuestro país se encuentra en la respuesta que desde el poder se dio a este tipo de acciones.

Siempre se ha tomado como ejemplo de la brutal represión ejercida desde el Estado español el famoso proceso de Montjuich en 1896, tras el atentado realizado en la calle Cambios Nuevos al paso de la procesión del Corpus de la iglesia de Santa María del Mar en Barcelona. Sin embargo, creo que muchas de las actuaciones que pusieron en marcha las autoridades durante la instrucción de este sumario tuvieron un claro precedente en la represión ejercida como respuesta a los atentados acaecidos en 1893 en la Ciudad Condal. En consecuencia, el objetivo de este artículo es analizar los primeros atentados anarquistas importantes perpetrados en nuestro país - las acciones en la Gran Vía barcelonesa, contra el General Martínez Campos, y el atentado en el Teatro del Liceo-y, de una manera especial, la consiguiente represión ejercida desde el Estado.

\section{EL ATENTADO DE LA GRAN VÍA DE BARCELONA}

Los atentados acaecidos en España a finales del siglo XIX se dirigieron contra los representantes políticos y militares del Estado y contra aquellos grupos sociales que, según los anarquistas, había que combatir. Los libertarios justificaban sus actos mediante una mezcla de venganza y simbolismo. Venganza como respuesta a la violencia ejercida desde el poder. Simbolismo porque su objetivo eran personas y grupos que representaban a los pilares de la organización social existente. En consecuencia, el atentado contra el Capitán General de Cataluña, Arsenio Martínez Campos, se debe entender como un ataque contra el militarismo y el Estado; mientras que las bombas lanzadas en el Teatro del Liceo fueron un acto contra el Capitalismo, encarnado por la burguesía catalana.

El primer gran atentado fue el que se produjo, el 24 de septiembre de 1893, contra el General Martínez Campos durante el desfile militar por las fiestas de la Merced en la Gran Vía barcelonesa. El anarquista Paulino Pallás arrojó dos bombas Orsini al paso del General. La explosión mató al guardia civil Jaime Tous, y causó varios heridos de diversa consideración entre el público que presenciaba la parada militar y entre los militares participantes en la misma. Martínez Campos sufrió una herida leve en la pierna derecha, y su ayudante, el señor Bustos, en el pe- 
cho. El general Castellvi resultó herido en el brazo derecho, mientras que el también general Molins fue atendido de diversas contusiones ${ }^{3}$.

Paulino Pallás, autor del atentado, era tipógrafo, tenía 31 años de edad y estaba casado con tres hijos ${ }^{4}$. Fue detenido en el mismo momento del atentado, pues no pretendió escapar. Tras arrojar las bombas, lanzó su gorra al aire mientras gritaba «¡Viva la Anarquía!», y esperó a que le detuvieran sin oponer resistencia ${ }^{5}$.

El autor señaló, en sus declaraciones, el carácter simbólico de su acción, pues dijo que no atacó a Martínez Campos por una cuestión personal, si no por su papel como representante de uno de los pilares de la sociedad, a la que detesta$b^{6}{ }^{6}$. Como señalaban sus correligionarios desde la prensa anarquista, Pallás:

«atacaba a una sociedad y sus instituciones; su acto era una inmensísima protesta en contra de los crímenes, las infamias y las torpezas sociales»?

Pallás sostuvo, desde el mismo momento de su detención, que había actuado en solitario. Sólo reconoció que las bombas se las había proporcionado un italiano llamado Francesco Momo, que había fallecido en marzo del mismo año, durante la manipulación de un artefacto que estaba fabricando en un taller de San Martín de Provenzals, Barcelona ${ }^{8}$. Lo que no fue obstáculo para que se sucedieran las redadas en la ciudad, en busca de los supuestos cómplices del atentado ${ }^{9}$. Las actuaciones policiales, bajo el mando del Gobernador civil, Sr. Larroca, y del inspector de policía Tressols, se dirigieron principalmente contra los anarquistas, que en desbandada salían apresuradamente de la ciudad. Las detenciones alcanzaban, de forma especial, a militantes del movimiento obrero, entre otros a los dirigentes que habían sido retenidos a bordo del acorazado «Pelayo» a raíz de los sucesos del $1 .{ }^{\circ}$ de mayo de $1891^{10}$.

Pallás fue juzgado por un Consejo de Guerra a los cinco días de su acción. El fiscal, coronel Ernesto García Navarro, aseguró, en sus conclusiones, que el detenido era el único autor, «pues no está demostrado que tuviera cómplices ni en-

3 Archivo del Instituto de Historia y Cultura Militar (AIHCM), legajo 157, telegrama del General Martínez Campos al Ministro de la Guerra, 24 de septiembre de 1893; y Diario de Barcelona, 25 de septiembre de 1893.

4 El Corsario (La Coruña), 1 de octubre de 1893.

5 SEMPAU, Ramón, Los victimarios, Barcelona, Manent y cia editores, 2. ${ }^{\circ}$ edición, 1901, p. 277.

6 Archivo General Militar de Segovia (AGMS), secc. 9, leg. R 62. Carta de Paulino Pallás desde el Castillo de Montjuich al director de El País, 3 de octubre de 1893, citada en La Anarquía, periódico comunista-anárquico (La Plata), 26 de octubre de 1895.

7 La Controversia (Valencia), 7 de octubre de 1893.

8 Archivo Nacional de París (ANP), F/7/12515. La muerte de Momo está recogida en un informe de E. Luienement, Comisario especial de Ferrocarril en Cergerè, remitido al Director de la Seguridad General en París, 15 de marzo de 1893.

9 Diario de Barcelona, 25 y 27 de septiembre de 1893.

10 Información del Diario Mercantil, citada en el Diario de Barcelona, 27 de septiembre de 1893. Una extensa lista de sumarios abiertos contra los anarquistas detenidos en esos días en el Diario de BarceIona, 28 de septiembre de 1893. 
cubridores». El acusado nunca se arrepintió de su acto, por lo que cuando el presidente del Tribunal, teniente coronel Juan Cirlot, le dio la palabra, éste se ratificó en su acción y dijo que sólo sentía «no haberlo consumado» ${ }^{11}$. El Consejo de guerra le declaró culpable, sentencia que fue ratificada por el Tribunal Supremo de Guerra y Marina. Pallás fue ajusticiado el 6 de octubre de $1893^{12}$. Los anarquistas le encumbraron como un héroe y un mártir:

«¡Cual mártir del Gólgota supo morir, después de sufrir el calvario que todos los esclavos del salario sufrimos!... ¡Salud o dignos mártires de la causa de los oprimidos! ¡Salud héroes de la lucha social! ¡Estas lágrimas costarán un río de sangre a la burguesía! ¡La venganza será terrible! »¹3.

El Corsario, periódico anarquista, reproducía, de esta forma, las últimas palabras pronunciadas por Pallás en el patíbulo momentos antes de morir: «iLa venganza será terrible! » ${ }^{14}$. Así que cuando el 7 de noviembre de 1893 - justo un mes después de su ejecución- dos bombas Orsini fueron arrojadas al patio de butacas del Teatro del Liceo durante el segundo acto de la ópera «Guillermo Tell», nadie dudó de la autoría de este terrible atentado.

\section{EL ATENTADO DEL TEATRO DEL LICEO}

La explosión causó 20 muertos y 27 heridos ${ }^{15}$. El gobierno suprimió inmediatamente las garantías constitucionales en la provincia. Las peticiones de una ley antiterrorista se sucedieron desde amplios sectores de la sociedad, especialmente desde aquellos que se habían visto directamente atacados, como eran las personas más influyentes de la sociedad catalana. No en vano, el atentado se había producido en el Teatro del Liceo, lugar emblemático de la burguesía en Barcelona.

Hay que destacar que en España no había a estas alturas una legislación específica que atendiera sobre los atentados realizados con explosivos. Ya en 1881, la fiscalía del Tribunal Supremo señalaba que la nueva utilización que se estaba dando a los «petardos» excedía de considerarse como «una cuestión de chicos» para convertirse, debido a las circunstancias y los tiempos, en «elementos de destrucción y de muerte». El ministerio fiscal entendía que se utilizaba impropiamente la palabra "petardo", pues estos explosivos causaban graves daños, levantamiento de raíles, destrozos de hilos y postes telegráficos e incluso la muerte. En consecuencia, defendía, por un lado, que el arrojar un «petardo» se considerase un delito, y no una falta, como sucedía hasta el momento; y, por otro, instaba

11 Diario de Barcelona, 30 de septiembre de 1893.

12 Diario de Barcelona, 27 de septiembre a 6 de octubre de 1893.

13 En el aniversario de su ejecución, El Corsario (La Coruña), 4 de octubre de 1894.

14 La Révolte (París), 6 de enero de 1894.

15 Archivo del Tribunal Superior de Justicia de Cataluña (ATSJC). Resumen de la causa. 
a que estas acciones se persiguieran aplicando determinados artículos del Código penal a la espera de la promulgación de leyes específicas ${ }^{16}$.

En los años posteriores, se intentó paliar las carencias de la legislación en vigor, tanto a través de su actualización de acuerdo con las necesidades del momento, como mediante la emisión de circulares que pretendían un mayor control del movimiento obrero, en general, y de la actividad anarquista, en particular. Así en febrero de 1892, una proposición de ley, que no fue aprobada, pretendía castigar la explosión de petardos con resultado de muerte o lesiones a personas o propiedades, o cuando estallasen dos o más petardos en una semana aunque no causaran daños, así como la confección o preparación de estos artefactos ${ }^{17}$. Dos meses más tarde, el Ministerio de Gobernación publicó una circular que tenía como fin el control de las asociaciones «cualquiera que sea su objeto, y muy especialmente de las que se relacionen con las clases obreras». El Ministerio recordaba, al mismo tiempo, la sentencia del Tribunal Supremo de fecha 28 de enero de 1884, según la cual:

«La Asociación fundada en la anarquía y el colectivismo con el propósito de emprender y sostener la lucha contra el capital, y de los trabajadores contra la burguesía, es contraria a la moral pública, pues contradice la autoridad y la propiedad industrial» ${ }^{18}$.

Nada más producirse el atentado contra el General Martínez Campos, el Fiscal del Tribunal Supremo recordó a los fiscales los artículos del Código penal a aplicar para impedir la propagación de la doctrina anarquista. En concreto señalaba el castigo como delincuentes a los que por medio de la imprenta, el grabado u otro medio mecánico de publicación provocaran directamente la perpetración de algún delito, y como autores de falta a quienes emplearan iguales medios para hacer apología de acciones calificadas como delito ${ }^{19}$. A finales de este año, una circular reservada del Ministerio de Gobernación solicitó a los gobernadores la confección de listas con los nombres de aquellos que defendieran las ideas anarquistas. Estas relaciones incluirían a los considerados como hombres de acción, a aquellos que fueran conocidos como propagandistas de la anarquía, mediante publicaciones, discursos o reuniones, y, en general, a toda persona de ideas ácratas. Las listas se complementarían con un informe de las escuelas anarquistas existentes en cada provincia en el que se haría constar su conexión con otros centros en la península, su influencia en las masas obreras y su actitud ante los atentados ${ }^{20}$.

${ }_{16}$ Archivo Histórico Nacional (AHN), secc. Gobernación, serie A, leg. 2 A, exp. N. ${ }^{\circ}$ 15. Circular de la Fiscalía del Tribunal Supremo, 20 de junio de 1881.

17 AHN, secc. Gobernación, serie A, leg. 2 A, exp. N. ${ }^{\circ}$ 17. Proposición de ley, 17 de febrero de 1892, contra los petardos que propuso el diputado Sr. García Romero.

${ }_{18}$ AHN, secc. Gobernación, serie A, leg. 2 A, exp. N. ${ }^{\circ}$ 17. Circular del Ministerio de Gobernación, 6 de abril de 1892.

19 AHN, secc. Gobernación, serie A, leg. 2 A, exp. N. ${ }^{\circ}$ 17. Circular del Fiscal del Tribunal Supremo, 17 de noviembre de 1893.

${ }^{20}$ AHN, secc. Gobernación, serie A, leg. 2 A, exp. N. ${ }^{\circ}$ 17. Circular del Ministerio de Gobernación, reservado, 14 de diciembre de 1893. 
Pero toda esta actuación se había quedado insuficiente con el brutal atentado del Liceo. Desde el conservador Diario de Barcelona se exigía la promulgación de nuevas leyes contra el anarquismo, mientras que otros periódicos liberales, como El Imparcial, que se había opuesto a la ampliación de la legislación vigente, clamaba ahora por la promulgación de “iLeyes especiales contra el anarquismo!»²1. Hasta en la propia prensa anarquista se criticaba este tipo de acciones porque, según decía, además de burgueses habían muerto «mujeres y niños». Acciones de estas características eran difíciles de asumir por buena parte de los libertarios, por mucho que, en las mismas páginas, no dejaran de acusar a la burguesía de vivir en medio del lujo sin preocuparse por la situación de la clase trabajadora ${ }^{22}$.

En definitiva, el Ministro de Gracia y Justicia del gobierno Sagasta, Trinitario Ruiz Capdepón, elaboró una ley antianarquista, aprobada el 10 de julio de 1894 , que venía a cubrir el vacío existente en el Código Penal de 1870 respecto a la utilización de explosivos. La nueva ley castigaba con pena de muerte o cadena perpetua a aquellos que empleando sustancias y aparatos explosivos causaran muerte o lesión a personas, o provocaran la explosión en edificio público, lugar habitado o donde hubiere riesgo para las personas. En el caso en que la explosión no se verificase, el castigo sería de presidio mayor en su grado máximo a cadena temporal en su grado medio. Pena similar tendría aquel que utilizara los explosivos para producir alarma. La ley castigaba también a los que fabricaran, facilitaran o vendieran sustancias o aparatos explosivos con penas de presidio correccional a presidio mayor cuando designasen, supiesen o sospechasen en que se iban a emplear. Se atendían, con diferentes penas, la conspiración, la amenaza o la inducción para cometer cualquier delito, ya fuera de palabra, por escrito, por la imprenta, el grabado u otro medio de publicación, así como la apología de estos delitos. Las asociaciones que facilitaran las acciones penadas por esta ley, serían declaradas ilícitas y disueltas. Una cuestión a subrayar es que la ley confiaba al Jurado el conocimiento en este tipo de causas. Por último, el Tribunal Supremo resolvería sobre los recursos planteados ${ }^{23}$.

Pero más allá de la aprobación de esta ley y su puesta en práctica, los sectores pudientes de la sociedad, que se sentían especialmente atacados en el último atentado, exigían resultados inmediatos. Así que la policía puso en marcha un fuerte dispositivo que implicó cientos de registros y detenciones, que no se circunscribieron exclusivamente a Barcelona, sino que se ampliaron a otros lugares de España, como Murcia, Valladolid y Granada ${ }^{24}$. A finales de 1893, según el Diario de Barcelona, el número de detenidos en la Ciudad Condal ascendía a $260^{25}$. Las cifras que manejaba la prensa anarquista eran muy superiores. El francés La Ré-

21 Diario de Barcelona, que cita el editorial de El Imparcial, 12 de noviembre de 1893.

22 La Révolte (París), 18 de noviembre de 1893.

23 Gaceta de Madrid, 11 de julio de 1894.

24 Diario de Barcelona, 2 de diciembre de 1893.

25 Diario de Barcelona, 29 de diciembre de 1893. 
volte apuntaba, a mediados de diciembre de 1893, que más de 300 compañeros habían sido detenidos ${ }^{26}$, mientras que a principios de enero elevaba a 500 el número de anarquistas encerrados en las prisiones de Barcelona, cantidad a la que había que añadir, según este periódico, los arrestados en otras ciudades de España, como Madrid, Valencia, Sevilla o Cádiz. Desde sus páginas se acusaba a la prensa liberal de ocultar toda esta información, y se señalaba que los diarios correligionarios españoles eran perseguidos por la autoridad. En concreto se mencionaba a El Corsario, acusado de hacer apología de Pallás, excitar a matar e incitar al pillaje ${ }^{27}$.

Lo cierto es que el número de encarcelados fue excepcional, como lo prueba la saturación de las cárceles de la ciudad y la necesidad de habilitar el barco «Navarra» como prisión provisional. Aquellos sobre los que se proyectaban mayores sospechas eran trasladados al castillo de Montjuich, donde se encontraban, a mediados de diciembre, 23 de los detenidos ${ }^{28}$.

Toda esta actuación pareció coronarse con éxito cuando el 19 de diciembre El Imparcial informaba del descubrimiento por parte de la policía del «complot anarquista que motivo la horrorosa catástrofe del Liceo». El periodista aseguraba que, según sus noticias, un preso llamado José Codina había declarado por fin «su bárbaro delito", por lo que le suponía "convicto y confeso de ser el autor del lanzamiento de la bomba que tantas víctimas produjo en el gran teatro". Codina, que seguía incomunicado en el castillo de Montjuich, había dicho tras su declaración: «Ya sabéis todo. Ahora que me maten, pues es lo único que espero ${ }^{29}$. En los días siguientes se fue completando la información. Se confirmó la participación de Codina y se descubrieron los complots anarquistas que motivaron los atentados de Martínez Campos y del Liceo, al tiempo que se nombraba a otro anarquista, Mariano Cerezuela, como participante en ambas acciones ${ }^{30}$. A Codina se le vinculaba, además, con un intento de atentado contra Martínez Campos, anterior al protagonizado por Pallás, y del que había desistido para no herir a la gente del pueblo que se encontraba en el lugar ${ }^{31}$.

Con el paso de los días, se registraron más autoinculpaciones. José Bernat era declarado convicto y confeso, el 26 de diciembre, por su participación en el atentado del Liceo ${ }^{32}$; tres días más tarde otro anarquista, Jaime Sogas, confesó ante el teniente de la Guardia civil, Narciso Portas, estar implicado en el mismo atentado. Con él eran ya 4 los que se habían declarado involucrados en este suceso ${ }^{33}$.

Sin embargo, las declaraciones de los detenidos, que se encontraban inco-

26 La Révolte (París), 17 de diciembre de 1893.

27 La Révolte (París), 6 de enero de 1894.

28 Diario de Barcelona, 19 de diciembre de 1893.

29 El Imparcial, 19 de diciembre de 1893.

30 El Imparcial, 22 de diciembre de 1893.

31 El Imparcial, 23 de diciembre de 1893.

32 El Imparcial, 26 de diciembre de 1893.

33 Diario de Barcelona, 29 de diciembre de 1893. 
municados, cambiaron sustancialmente en los días siguientes. El Diario de Barcelona aseguraba que José Codina Juncá, de 21 años y cerrajero de profesión, después de 8 días de interrogatorios, se había declarado autor de cuatro bombas Orsini con las que había querido matar al general Martínez Campos, en el atentado señalado más arriba, el día 24 de junio último en una parada militar en la calle de San Juan. Codina se hacía también responsable de la explosión de un paquete con siete cartuchos el día 2 de noviembre de 1892 en un banco próximo al domicilio del juez municipal de San Feliu de Guixols ${ }^{34}$. Pero manifestaba que no tenía ninguna participación en el crimen del Liceo y menos en el atentado de Martínez Campos, pues, según sus declaraciones, no conoció a Pallás hasta después del atentado ${ }^{35}$.

A este respecto, hay que señalar que las detenciones por estos importantes atentados y los consiguientes interrogatorios solían servir, entre otras cosas, para solucionar los casos sin resolver que se agolpaban en las comisarías de policía. En las actuaciones llevadas a cabo durante este proceso, además de las autoinculpaciones de Codina, se encuentra la confesión del anarquista Luis Comas, que fue uno de los trasladados desde el crucero "Navarra» al Castillo de Montjuich. Allí declaró haber dirigido al grupo que atacó a las fuerzas del cuartel del Buensuceso, el 2 de agosto de 1891, por lo que fue entregado a la justicia militar ${ }^{36}$. Estos esclarecimientos, más allá de la veracidad de las confesiones, siempre difícil de verificar, pueden tener dos explicaciones: la policía utilizaba estas redadas para «solucionar» los casos pendientes; o los declarantes preferían hacerse cargo de algún acto que, aunque grave, no implicara una más que segura condena a cadena perpetua o incluso la pena capital.

Información similar aparecía en El Imparcial, donde se aseguraba que aunque Codina se había declarado, en un primer momento, constructor de la bomba y autor material del lanzamiento, «negativas posteriores» y falta de detalles habían supuesto rebajar su implicación en el atentado, ahora como coautor ${ }^{37}$. Por su parte, Mariano Cerezuela negaba ahora su participación, y los otros dos «convictos y confesos» de la acción, José Bernat y Jaime Sogas, señalaban a un tal Santiago Salvador como autor ${ }^{38}$.

La situación cambió definitivamente cuando el 2 de enero de 1894 era detenido en Zaragoza el tal Salvador, que se confesó único autor del atentado ${ }^{39}$. Esta circunstancia ponía en entredicho los medios para conseguir las confesiones, y las acusaciones que se vertían sobre las autoridades de malos tratos tomaban visos

${ }^{34}$ ANP, F/7/12725, informe del Comisario Especial de Saint Laurent de Cerdans al Director de la Seguridad General en París, el 4 de enero de 1894; y Diario de Barcelona, 31 de diciembre de 1893

35 Diario de Barcelona, 31 de diciembre de 1893.

36 Diario de Barcelona, 13 de enero de 1894.

37 El Imparcial, 3 de enero de 1894.

38 Diario de Barcelona, 31 de diciembre de 1893.

39 Diario de Barcelona, 2 de enero de 1894. 
de realidad. Mariano Cerezuela, junto con otros detenidos, denunció, mediante carta al diario republicano El País, las torturas a las que había sido sometido: fusilamientos simulados, retorcimiento de genitales, golpes, etc ${ }^{40}$. Torturas que, como no podía ser de otro modo, aparecían profusamente en los periódicos anarquistas, como era el caso de La Révolte, que en su información sobre España, se hacía eco, con todo lujo de detalles, de los malos tratos recibidos por Codina, Cerezuela y el resto de detenidos ${ }^{41}$. Alguno de los cuales murió en las cárceles barcelonesas, como el anarquista Altafulla, que había sido arrestado a raíz del atentado de la Gran Vía ${ }^{42}$, o Miguel Nacher, detenido tras el atentado del Liceo; otros no llegaron al juicio, como Juan Bernich ${ }^{43}$, que estaba acusado, junto a Codina, de mandar construir las bombas ${ }^{44}$; o se suicidaron en prisión, como Martín Borrás, que, desesperado, consiguió su propósito al tercer intento:

«...cansado de vivir en un mundo de injusticias... Aquí en la cárcel veo con más claridad las injusticias sociales y me horroriza además tanta sed de sangre inocente, como acontece en los actuales momentos. Me pesa ser una carga para la familia... Y aunque me dieran la libertad no resultaría menos una carga, dado mi estado impedido...» ${ }^{45}$.

Hasta en la información que aparecía en el Diario de Barcelona, se recogían hechos difícilmente explicables, como el "paseo» que dio una noche Cerezuela con la Guardia civil por el campo de la Bota, en el que el detenido se arrojó al mar con objeto de suicidarse ${ }^{46}$. Con relación a este hecho, años más tarde, un anarquista, que prefirió mantenerse en el anonimato, y decía haber compartido reclusión con Cerezuela, contaba que éste una noche fue conducido por el teniente Portas a un barranco sobre la playa, donde fue torturado para que firmara una declaración en la que se inculpara y denunciara al autor del atentado ${ }^{47}$.

A estas denuncias se unía la realidad de que el principal encausado, José Codina, se había declarado autor del atentado cuando él no había arrojado las bombas, lo que corroboraba, de forma implícita, que su declaración no había sido obtenida de forma legal. Era evidente que nadie iba a aceptar la culpabilidad de un atentado de estas características, que con toda probabilidad le costaría la vida, si

40 SEMPAU, Ramón (1901), pp. 279-280.

41 La Révolte (París), 20 de enero de 1894.

42 Diario de Barcelona, 13 de diciembre de 1893

43 Según El Imparcial, Juan Bernich murió en el hospital del pueblo de Prats de Llusanés, y era el único anarquista que quedaba por prender. Ignacio Agustí señala que murió en dicho hospital al dispararse un tiro mientras huía. AGUSTí, Ignacio, «Una bomba en el Teatro del Liceo», Historia y vida, año VI, n. ${ }^{\circ}$ 63, junio 1973, pp. 76-91. Sin embargo, Álvarez Junco señala que Bernich murió en la cárcel al poco de ser detenido, ÁLVAREZ JUNCO, José, El emperador del Paralelo. Lerroux y la demagogia populista, Madrid, Alianza Editorial, 1990, p. 149.

44 Diario de Barcelona, 1 de mayo de 1894, juicio contra Codina y otros.

45 Instituto Internacional de Historia Social de Amsterdam (IIHS), fondo Salud Borrás, carta de Martín Borrás, desde la cárcel de Barcelona, a su mujer Francisca Saperas Miró, 7 de mayo de 1894.

46 Diario de Barcelona, 31 de diciembre de 1893.

47 Les Temps Nouveaux (París), 3 de octubre de 1896. 
no mediaran torturas en la obtención de su confesión. Esta circunstancia fue reconocida, años más tarde, por el capitán general de Cataluña, Emilio Despujol, al referirse a:

«la circunstancia agravante de que la causa del Liceo fue instruida por la jurisdicción ordinaria, y que los supuestos tormentos fueron entonces, según la voz pública, en los calabozos del Gobierno Civil, actuando como inmediato ordenador de dichos tormentos el propio Sr. Larroca, y no sólo se hizo alguna mención de tales violencias en el plenario y en alguna defensa, sino que vino a prestarles aparentes visos de verdad, el hecho de que habiendo acabado por confesarse el reo Codina autor del hecho de haber arrojado la bomba del Liceo, que más tarde fue aprehendido el verdadero autor, Salvador, y se probó que Codina era inocente de tal delito... ${ }^{48}$.

A pesar de todas estas circunstancias, el Gobernador civil de Barcelona, Ramón Larroca, aparecía en los medios de comunicación como el verdadero artífice del descubrimiento del supuesto complot, por lo que recibía continuas muestras de reconocimiento por su labor al frente de las investigaciones. Pero a nadie se le escapaba que igualmente concitaba odios entre los anarquistas que eran perseguidos. Por eso pocos fueron los sorprendidos cuando el 25 de enero de 1894, un individuo introdujo su brazo por la portezuela de su coche y disparó un tiro de pistola sobre Larroca a la puerta del Gobierno Civil. El disparo hirió al gobernador en el carrillo izquierdo, alojándose el proyectil en el hueso maxilar inferior. El señor Ubaldo de Aspiazu, secretario del Gobierno, que iba con él en el coche, bajó del carruaje y detuvo al agresor, impidiendo que realizase un segundo disparo, pues se preparaba para amartillar de nuevo el arma. Ramón Murull Comas, de 37 años y profesión albañil, fue el autor del atentado ${ }^{49}$.

La policía se movilizó inmediatamente, y esa misma noche eran ya diez los detenidos. Aunque en un principio no se identificó al autor de los disparos como anarquista, las pesquisas se dirigieron en la misma dirección que en los otros atentados, es decir, círculos ácratas; y al igual que en los casos interiores, la policía volvió a descubrir el «complot anarquista» de un grupo que se reunía en un almacén, casa o café, y que había preparado el atentado contra el Gobernador ${ }^{50}$. Junto a Ramón Murull fueron inculpados Ramón Felip Mas, de 37 años, camarero; Baltasar Balleras Sirvent, de 45 años, jornalero; y Ramón Carné Sans, de 41 años, jornalero ${ }^{51}$. Todos ellos firmaron una declaración de inculpación en el Gobierno civil, de la que en el momento del juicio se retractaron por haber sido arrancada «a fuerza de martirios ${ }^{52}$. El abogado defensor, Puig de Asprer, presentó

48 AlHCM, 2. , 4. $^{\text {a }}$ leg. 157, providencia del Capitán General de Cataluña, Emilio Despujol, en el caso de Cambios Nuevos, 30 de noviembre de 1899.

49 Diario de Barcelona, 26 de enero de 1894.

50 Diario de Barcelona, 27 de enero de 1894.

51 Archivo de la Corona de Aragón (ACA), sentencia del juicio contra Ramón Murull y otros, 10 de julio de 1894.

52 El Corsario (La Coruña), 6 de septiembre de 1894, palabras de Baltasar Balleras. 
como testigos en la vista a varios de los procesados por la causa del Liceo, a quienes formuló preguntas sobre los métodos utilizados por los oficiales de la Guardia civil en las primeras declaraciones tras las detenciones. La presidencia del tribunal declaró estas preguntas impertinentes y, ante la actitud de desagrado del público, amenazó con desalojar la sala ${ }^{53}$.

Todas estas circunstancias y, principalmente, la detención de Santiago Salvador, y su posterior confesión, deberían haber implicado la apertura de una investigación que aclarara de forma nítida la manera en la que se había conseguido las confesiones de los detenidos en el atentado del Liceo y su verdadera implicación en los hechos. Sin embargo, todo parece indicar que el Estado no quiso dar una imagen de «debilidad» $y$, en lugar de esclarecer lo sucedido, buscó los medios para dar un escarmiento a los anarquistas que, más allá de este acto terrorista, consideraba sus enemigos. Así que la causa por el atentado contra el general Martínez Campos se reabrió, y los encausados hasta ese momento por la bomba del Liceo pasaron a ser acusados como cómplices de Paulino Pallás.

El Consejo de Ministros, presidido por Sagasta, ya había abordado, a los pocos días del atentado del Liceo, la cuestión referente a la posible conexión entre los dos atentados que había sufrido la capital catalana en los meses anteriores. Según las informaciones, el consejo había deliberado largamente:

«de si procedía o no considerar los sucesos del Liceo de Barcelona como delito conexo del atentado de Pallás contra el general Martínez Campos, y después de mucho discutir los ministros letrados, acordaron considerarlos como delitos aislados» ${ }^{54}$.

Sin embargo, las informaciones que aparecieron tras la detención de Salvador incidían en la conexión entre ambas acciones. Así, el mismo día de su arresto ya se le señalaba como asistente a «las reuniones que celebraban los anarquistas terroristas en la cervecería de la calle Diputación», en donde confraternizó, según esta información, con Pallás, Codina y Cerezuela ${ }^{55}$. Por su parte, los detenidos negaban su participación en ambos atentados. Lo cierto es que no hay ningún indicio de la existencia de un complot en el caso del atentado contra el General Martínez Campos, mientras que si hay pruebas de contactos y hasta de encubrimiento de Salvador tras la realización de su acción, aunque no de una trama para cometer el atentado del Liceo.

En efecto, hay que señalar que Salvador no estaba en Barcelona en el momento del atentado contra el General, pues había salido de Barcelona al inicio de ese verano con dirección a Valencia, y no volvió a la capital catalana hasta des-

53 Diario de Barcelona, 10 de julio de 1894.

54 Diario de Barcelona, 11 de noviembre de 1893.

55 Diario de Barcelona, 2 de enero de 1894.

56 El Imparcial, 4 de enero de 1894. 
pués de dicho atentado ${ }^{56}$. Además siempre declaró que no estuvo implicado en el atentado protagonizado por Pallás, a quien dijo que sólo conocía de vista ${ }^{57}$. Declaraciones que contrastan con la relación que mantuvo con los detenidos por el caso del Liceo. En primer lugar, hay que recordar que fueron éstos quienes, a través de sus declaraciones, pusieron a la policía tras los pasos de Salvador. Así José Bernat declaraba, a finales de diciembre de 1893, que junto a Cerezuela había oído en casa de un anarquista que un tal Salvador se había declarado autor de dicha acción ${ }^{58}$. Por su parte, Salvador reconoció que tras arrojar las bombas permaneció unos días en Barcelona —en el juicio declaró que en casa de Sogas ${ }^{59}$ , para luego salir con dirección a Barbastro acompañado de Cerezuela y, según informaciones periodísticas, de Codina ${ }^{60}$. Éste se había dirigido a la frontera donde había sido interceptado por la policía francesa ${ }^{61}$ y de vuelta a Barcelona fue detenido en las inmediaciones de la fábrica donde trabajaba62. Por su parte, Cerezuela, según declaraciones del propio Salvador durante el juicio del Liceo, se había negado a entregarle unas bombas que le había pedido, con el propósito de arrojarlas en la Plaza de la Paz entre las autoridades que formaban parte del cortejo fúnebre en el entierro de las víctimas ${ }^{63}$. También le identificó como la persona que le había proporcionado un frasco con veneno para quitarse la vida en el caso de ser detenido ${ }^{64}$. En fin, mientras que parecen evidentes los contactos en el caso del Liceo tras la realización de la acción, no hay ninguna prueba que atestigüe la existencia de una trama en el caso de la Gran Vía. Ni siquiera en el juicio por el atentado del Liceo, cuando ya todos los principales detenidos habían sido fusilados, Salvador admitió haber tenido relaciones con Pallás, mientras que reconoció sus contactos con el resto de los ejecutados.

\section{JURISDICCIÓN MILITAR VERSUS JURISDICCIÓN CIVIL}

Toda esta situación dio lugar, en su momento, a que la confusión se adueñara tanto sobre la delimitación de los hechos y sus autores, como de la jurisdicción militar o civil que se tenía que hacer cargo del proceso. Asunto que no era baladí, como a continuación se podrá comprobar, pues la justicia militar era tremendamente más expeditiva que la civil. El atentado contra el General Martínez Campos, en la Gran Vía barcelonesa, en el que había muerto un guardia civil, había sido juzgado, como se recordará, por la jurisdicción militar. Sin embargo, en el atentado del

57 Diario de Barcelona, 12 de julio de 1894.

58 Diario de Barcelona, 31 de diciembre de 1893.

59 El Imparcial, 12 de julio de 1894.

60 El Imparcial, 3 de enero de 1894.

61 ANP, sig. F/7/12725, informe del Comisario Especial de Saint Laurent de Cerdans al Director de la Seguridad General en París, 4 de enero de 1894.

62 El Imparcial, 19 de diciembre de 1893.

63 Diario de Barcelona, 12 de julio de 1894.

64 El Imparcial, 12 de julio de 1894. 
Liceo no hubo ninguna víctima castrense, con lo que la jurisdicción civil fue la encargada de entender en este asunto. A pesar de estas circunstancias, mientras que en la primera quincena de enero se aseguraba que los detenidos como consecuencia del atentado del Liceo, continuaban sujetos al tribunal ordinario ${ }^{65}$; luego se supo que habían pasado a la jurisdicción militar ${ }^{66}$.

Así las cosas, desde el Diario de Barcelona se intentó explicar como era posible que la causa por el atentado de la Gran Vía se reabriera cuando ya había sido ejecutado el autor de la acción y el por qué del traspaso de jurisdicciones. La información subrayaba que la autoridad militar instruyó, a raíz del atentado contra Martínez Campos, causa contra diferentes individuos, uno de los cuales era Paulino Pallás. Al ser confeso del atentado, la instrucción quedó despejada respecto a él, y en conformidad al Código procesal militar se formó para Pallás pieza separada, de la que entendió el juez militar señor Obregón, y que terminó con el fusilamiento del anarquista. La causa matriz que se seguía contra los otros comprometidos quedó en poder del juez militar señor Martínez. Tras el atentado del Liceo, el juez civil García Domenech se encontró con que algunos anarquistas sometidos a su jurisdicción resultaban también comprometidos en el atentado de la Gran Vía, por lo que los envió al juez militar Martínez, que los incluyó en la causa principal de la Gran Vía. Como estos procesados se hallaban en condiciones que permitían una más rápida instrucción de la causa, como había sucedido con Pallás, se formó respecto a ellos otra pieza separada. De esta última se hizo cargo otro juez militar, Enrique Marzo. En resumen, había una causa principal sobre el atentado de la Gran Vía que seguía el juez Martínez. Una pieza separada de ésta, de nueva creación, de la que se encargaba el juez Marzo, contra los implicados en el atentado de la Gran Vía, pero que habían sido detenidos durante las diligencias del Liceo. Estos últimos quedaban, al mismo tiempo, sometidos al juez García Domenech por este último atentado ${ }^{67}$.

El juez Enrique Marzo presidió el Consejo de Guerra que se celebró en Barcelona el 29 de abril de 1894. Los 10 acusados eran: Mariano Cerezuela, Jaime Sogas, Manuel Archs, José Sabat, José Bernat, José Codina, Juan Carbonell, Rafael Miralles, Domingo Mir y Francisco Vilarrubias. Desde medios periodísticos se recalcaba, como nota relevante, la falta de información que rodeaba la vista, la ausencia de cualquier paisano y hasta la composición del tribunal, pues era:

«imposible averiguar con exactitud los nombres de los vocales. Parece que todos están juramentados para no comunicar a la prensa cualquier detalle»68.

El fiscal, Ernesto García Navarro, basó parte de su intervención en demostrar

\footnotetext{
65 El Imparcial, 8 de enero de 1894.

66 El Imparcial, 17 de enero de 1894.

67 Diario de Barcelona, 17 de enero de 1894.

68 El Imparcial, 2 de mayo de 1894.
} 
que Paulino Pallás no había actuado en solitario. Según su argumentación Pallás pertenecía a un grupo de acción — que recibía el nombre de «Benevento»69-que había conspirado contra el General Martínez Campos. El fiscal defendía que dos o tres días antes del 24 de septiembre, fecha del atentado, cinco miembros del grupo, Pallás, Cerezuela, Sogas, Archs y Sabat, se reunieron en la cervecería de la calle Diputación y acordaron llevar a cabo la acción. El fiscal aportaba como única prueba que todos ellos, en sus declaraciones, se denunciaron unos a otros y reconocían la existencia de la reunión que finalizó con el acuerdo de matar al general. De todas formas, García Navarro no podía sustraerse a las manifestaciones y actas del consejo de guerra que habían condenado a Pallás como autor en solitario del atentado, por lo que apostilló:

«No se diga que no estaban allí los conspiradores todos, que en los autos no consta su presencia y que no existe lo que no está escrito, tanto más cuanto que se intenta probar lo contrario».

El fiscal acusó a Codina de mandar construir las bombas. A Bernat de ocultar los artefactos en un campo frente a su casa, y de ser la persona que las entregó a Cerezuela, que a su vez las hizo llegar a Pallás. A Sogas, Archs y Sabat les acusó de cooperar en el delito, mientras que a los cuatro encausados restantes les imputó el delito de complicidad. En consecuencia, pidió la pena de muerte para Cerezuela, Sogas, Archs, Sabat, Bernat y Codina, como coautores por inducción o cooperación, y la de cadena perpetua para Carbonell, Miralles, Mir y Villarrubias, como cómplices ${ }^{70}$. Hay que hacer notar como, en la versión aportada, en esos momentos, por el fiscal, Santiago Salvador no aparece en las supuestas relaciones entre el grupo.

La sentencia se cumplió el 21 de mayo de 1894 a las 4,30 de la mañana, momento en el que los seis anarquistas eran fusilados en el foso del recinto interior del Castillo de Montjuich, entre la luneta de tierra y la lengua de sierpe ${ }^{71}$.

Toda esta actuación contrasta con lo acontecido en el juicio por la vía civil, celebrado el 11 de julio de 1894 en la Audiencia Provincial con Jurado popular por el atentado del Liceo, contra Santiago Salvador, por 20 asesinatos consumados y 27 frustrados ${ }^{72}$. El acusado, de 28 años de edad, de profesión jornalero y estado civil casado, no tenía antecedentes penales, aunque estaba reclamado por el Juzgado de Instrucción del distrito de San Vicente de Valencia, por el delito de estafa. En la presente causa, que se juzgó de acuerdo al Código Penal vigente, Salvador aparecía como autor del atentado acompañado de otras muchas personas incluidas en

69 Diario de Barcelona, 12 de enero de 1894.

70 Diario de Barcelona, 1 de mayo de 1894.

71 Diario de Barcelona, 21 de mayo de 1894.

72 ATSJC, resumen del juicio por el atentado del Teatro del Liceo.

73 Eran los casos de Alberto Soldani, Juan Aragón, Ramón Fontanals, Alfredo Rugiero, Carlos Francisco Noel, José Guillot, Domingo Mir, Juan Carbonell, Mateo Ripoll, Domingo Fruitos, Rafael Miralles, Alfredo Bacherini, Francisco Villarrubias, Ramón Romero, José Prats y Antonio Alfaro. 
el mismo atestado. Para dieciséis de ellas la causa fue sobreseída ${ }^{73}$; mientras que Jaime Prats y N. Carcañá fueron declarados en rebeldía; en cuanto a Miguel Nacher, José Codina, Mariano Cerezuela, José Bernat, Jaime Sogas, Manuel Archs y José Sabat, su responsabilidad criminal se declaró extinguida por haber fallecido. Los seis últimos eran los incluidos en el sumario de la Gran Vía, que habían sido recientemente fusilados. Como Nacher murió en la cárcel, el único declarado culpable por el Jurado fue Santiago Salvador ${ }^{74}$.

Hay que subrayar que en el grupo sobre el que se sobreseyó la causa, se encontraban Mir, Carbonell, Miralles y Villarrubias, que habían sido condenados a cadena perpetua en el anterior Consejo de Guerra. Además, en este grupo estaban presentes José Prats y Antonio Alfaro; el primero explicó como medió con Sogas para que admitiera a Salvador como huésped en su casa; el segundo fue la persona que hospedó a Salvador en su pueblo, Castellseras, durante su huida. Ambos, a pesar de reconocer la ayuda prestada al acusado, negaron su participación en el delito. El fiscal retiró la acusación que había contra ambos como encubridores $^{75}$. Por su parte, el principal acusado reconoció sus contactos con Cerezuela y la amistad que le unía con Sogas, aunque negó que conociera a algunos de los anarquistas fusilados.

El fiscal, en su exposición final, censuró no sólo a aquellos que profesaban ideas anarquistas, sino también a los periódicos que daban noticias que no deberían hacerse públicas. Calificó de fiera a Salvador y, con unas palabras que dejaban clara la atmósfera que se respiraba, dijo:

«Señores jurados, voy a concluir con dos palabras. ¿Quieren guerra esos señores?; pues a defenderse» ${ }^{76}$.

El juez Agustín Moreno, en el resumen, apoyó la calificación del fiscal de los hechos acaecidos como de estragos. Esta extraña calificación se debía a que era la única opción de juzgar el atentado de acuerdo con las leyes vigentes, pues, como ya se ha señalado, España no contaba con una ley que entendiera de las acciones realizadas mediante explosivos. Precisamente la ley antianarquista, que se había promovido tras el atentado del Liceo, fue aprobada el 10 de julio de 1894, es decir, un día antes del presente juicio. En consecuencia, como señalaba el juez, en 1870, año en el que se publicó el Código penal español en uso, no se conocían los explosivos por medio de la dinamita, ni se soñaba siquiera que se utilizaran de la forma que los estaban haciendo, por lo que en la disposición legal que se refería a los estragos se hablaba sólo de incendios, rotura de redes telegráficas y corte de rieles de líneas férreas, y no de materias explosivas ${ }^{77}$.

El Jurado condenó a Santiago Salvador a la pena de muerte a garrote vil por

\footnotetext{
74 ACA, sentencia contra Santiago Salvador, 11 de julio de 1894.

75 El Imparcial, 12 de julio de 1894.

76 Diario de Barcelona, 12 de julio de 1894.

77 Diario de Barcelona, 12 de julio de 1894.
} 
los asesinatos consumados, y a la de 17 años de cadena temporal, en caso de ser indultado, por cada uno de los asesinatos frustrados; además se le condenaba a indemnizar con 10.000 y 15.000 pesetas a dos de las familias de las víctimas ${ }^{78}$. Como se puede comprobar, la actuación del Jurado había sido mucho más ajustada a ley que la llevada a cabo por la jurisdicción militar, pues condenó a muerte al autor confeso de los hechos y dejó en libertad a aquellos sobre los que no había pruebas suficientes de su culpabilidad.

Esta circunstancia está presente también en el juicio contra Ramón Murull, como autor, y contra Ramón Felip, Baltasar Balleras y Ramón Carné como cómplices por el atentado que hirió al Gobernador civil, Larroca. El juicio con Jurado coincidió en el tiempo con el de Salvador, pues se celebró el 9 de julio de 1894. Las circunstancias que rodearon el atentado, las detenciones y la vista bien merecen una breve recapitulación. El Gobernador, además de por su labor contra del anarquismo, se había destacado en la ciudad por su lucha contra el juego y sus intentos de reglamentar las actividades de esta clase que estaban prohibidas ${ }^{79}$. Pues bien, resulta que Murull había dilapidado la herencia de su familia en el «tapete verde», motivo por el que había intentado suicidarse de un tiro ${ }^{80}$. El autor del atentado aportó en la vista una versión de los hechos verdaderamente increible; según la exposición de su abogado, Murull no tenía nada que ver con el anarquismo, y no tuvo nunca la intención de matar a Larroca. Decía estar desesperado por la miseria a la que le había empujado su afición por el juego, por lo que, ante la falta de valor para quitarse la vida, disparó contra el carruaje del gobernador, sin saber quien iba dentro, con el único propósito de que los agentes del orden abrieran fuego contra él y le mataran. El abogado también salió al paso de otra de las versiones que estuvo omnipresente en la vista, al calificar de inverosímil la suposición de que los principales perjudicados por la actuación del Gobernador con los locales de juego hubieran pagado a Murull para realizar el atentado. Respecto a los otros tres detenidos, la defensa negó cualquier complicidad pues, según su versión, se encontraban en la plaza donde ocurrieron los hechos por casualidad.

Esta relación de Murull con el juego y los odios concitados contra el Gobernador entre los dueños del juego, unidas a las incertidumbres suscitadas tras su detención sobre su militancia anarquista —que volvió a ser negada durante la vista-, y las denuncias de malos tratos con los que, supuestamente, se habían obtenido las autoinculpaciones, fueron suficientes para crear una duda más que razonable entre los miembros del Jurado. Aunque quizá habría que decir dudas, pues con estas premisas, tanto la complicidad de los otros tres encausados, como el móvil del atentado quedaban en entredicho. Así lo debió entender el fiscal cuando quiso asegurarse el veredicto de culpabilidad contra el autor, más allá del motivo, al calificar el hecho de asesinato frustrado contra el Gobernador civil:

78 ACA, sentencia contra Santiago Salvador, 11 de julio de 1894.

79 GONZÁLEZ CALLEJA (1998), p. 277.

80 El Imparcial, 10 de julio de 1894. 
«...fuese cual fuese el móvil del hecho: ya el anarquismo, la venganza personal o de los dueños de establecimientos de juego despechados por no permitirse los juegos prohibidos por la ley ${ }^{81}$.

En consecuencia, el ministerio fiscal, en sus conclusiones, acusó a Ramón Murull como autor y a los otros tres encausados como encubridores del delito. Para el primero solicitó 17 años de cadena temporal y para cada uno de los restantes 10 años de presidio mayor. Sin embargo, el Jurado, al igual que había sucedido en el juicio por el atentado del Liceo, sólo condenó a aquel sobre el que existía la prueba irrevocable de su participación en los hechos. Por lo tanto, condenó a Ramón Murull a 17 años de cadena temporal, mientras que Ramón Felip, Baltasar Balleras y Ramón Carné fueron absueltos ${ }^{82}$.

Es evidente que no era lo mismo qué clase de jurisdicción entendiera en los delitos de terrorismo. Así que, después de todo lo expuesto, la utilización de la justicia militar en casos como el de los detenidos por el atentado del Liceo y luego juzgados en Consejo de Guerra por su supuesta colaboración con Pallás nos puede sugerir una doble interpretación, cuando no una mezcla de ambas. Por un lado, la determinación desde el poder de aplicar mano dura contra el anarquismo. Actuación que buscaba más el escarmiento que la justicia, y donde la respuesta del Estado se planteaba como una guerra contra un adversario al que había que intimidar y erradicar. Por otro, la desconfianza ante la fortaleza de los ciudadanos que formaban parte de los jurados, pues se temía que el miedo a sufrir alguna represalia facilitara la absolución de los encausados. A este respecto, son suficientemente elocuentes las palabras finales del periodista que cubrió la información sobre el juicio contra Salvador;

«Es un dato consolador la energía con que ha procedido este jurado apreciando cuantas circunstancias agravantes concurren en el crimen tremendo del Liceo y condenado a muerte al anarquista Salvador... Los jurados de Barcelona no se han dejado intimidar, como los que juzgaron a Ravachol, por las amenazas de esos criminales... Celebramos, por tanto, el valor cívico del jurado barcelonés ${ }^{83}$.

Salvador fue ejecutado el 21 de noviembre de 1894. Al subir al patíbulo gritó: «¡Viva la revolución social! ¡Mueran las religiones todas! ¡Viva la anarquía!». Sentado en el banquillo cantó el himno anarquista y luego repitió que «moría por la idea». El Corsario, periódico anarquista, terminaba su información con la siguiente frase: «Loor a los que saben morir por la más noble de las causas, la más bella de las ideas, LA ANARQUÍA» ${ }^{84}$.

81 Diario de Barcelona, 10 de julio de 1894.

82 ACA, sentencia contra Ramón Murull, 10 de julio de 1894.

83 El Imparcial, 12 de julio de 1894.

84 El Corsario (La Coruña), 29 de noviembre de 1894. 


\section{CONCLUSIONES}

A modo de análisis sobre la represión ejercida como consecuencia de los atentados acaecidos en 1893 en Barcelona, hay que subrayar que la respuesta del Estado, principalmente tras la masacre del Liceo, complicó de una forma excepcional el problema del terrorismo en España. Su actuación estuvo viciada, y dio lugar a una espiral que desembocó en actos cada vez más cruentos de imposible justificación por ambas partes.

En primer lugar, hay que referirse a la utilización de métodos ilegales tan deleznables como la tortura. En su uso se encuentra el origen de buena parte de todos los males que acumuló el Estado en su actuación. Es cierto que las denuncias de tortura solían aparecer en el mismo momento de las detenciones, y que siempre es muy difícil desmentir o corroborar estas acusaciones. Sin embargo, en el caso que nos ocupa, parece evidente que las torturas existieron. No se entiende de otra forma que, según reconoció el propio Capitán General de Cataluña, Emilio Despujol, Codina se confesara autor del atentado siendo inocente, sabiendo que su declaración le costaría la vida. Lo mismo se puede decir del resto de acusados, pues pasaron de confesar su participación en el atentado del Liceo, a ser juzgados por el intento de asesinato del General Martínez Campos. En este último juicio, además, el fiscal sólo presentó como prueba de la intervención de los 10 encausados las declaraciones en las que unos a otros se señalaban como implicados. Prueba poco consistente si tenemos en cuenta el modo ilegal con las que fueron obtenidas.

Precisamente, la apertura de una pieza separada del atentado de la Gran Vía, por el que había sido juzgado Pallás, es la segunda actuación poco clara de las autoridades en este asunto. Todo indica que ante la presión de los sectores más pudientes de la sociedad la represalia se impuso a la justicia o, cuando menos, la desproporción en su aplicación, innegable entre la acción y el castigo. Así lo demuestra la ejecución de seis personas por supuesta complicidad, cuando ya había sido ejecutado el autor material del atentado. Además hay que subrayar la falta de transparencia de la jurisdicción militar, que hubiera sido imprescindible en casos tan excepcionales como el presente. A esta realidad habría que añadir la circunstancia agravante de que la posible relación del grupo ejecutado era más evidente con el autor del atentado del Liceo, que con el que intentó acabar con la vida del General Martínez Campos. Actuar de acuerdo a estas evidencias hubiera supuesto la presencia de los detenidos ante un tribunal civil lo que, a la vista de lo relatado más arriba, hace suponer un veredicto más ajustado a derecho que el emitido por el consejo de guerra.

Es factible que los atentados anarquistas de esta época contaran con la colaboración de varias personas en su realización. De hecho, parece evidente la existencia de «grupos de acción» con una mínima infraestructura, que abarcaba desde la persona que fabricaba las bombas hasta el autor del atentado, pasando 
por los encargados de la compra del material explosivo y su ocultación. Pero el conocimiento de la ideología, tremendamente individualista, de estos «hombres de acción", unido a la falta de redes jerarquizadas, inexistentes en el Movimiento Libertario, implicaban que estos atentados terroristas pudieran ser consecuencia, en última instancia, de un acto individual, más que de una acción premeditada y planificada por el grupo. Cualquiera de sus miembros tenía la autonomía suficiente para realizar un atentado sin contar con el conocimiento ni, mucho menos, la autorización del resto, que se enteraban una vez realizada la acción.

Estas circunstancias están presentes en la acción de Pallás o de Salvador, pero también parece formar parte de la interpretación del Estado. De hecho, Pallás se había declarado autor en solitario del atentado y, por las palabras del fiscal durante la vista, la celeridad con la que fue juzgado y ejecutado — desde el día del atentado hasta su ejecución transcurrieron tan sólo 12 días-, nada indica que la justicia tuviera la más mínima duda al respecto. En caso contrario, seguramente, la instrucción se hubiera alargado y, en ningún caso, se hubiera ejecutado a Pallás sin antes obtener toda la información posible sobre sus presuntos colaboradores. Hay que subrayar que solamente tras conocerse la identidad de Salvador como autor del atentado del Liceo, cuando ya los detenidos por esta acción se habían declarado convictos y confesos, se comenzó a hablar de la supuesta relación de estos últimos con Pallás.

En el caso del Liceo, Salvador en sus declaraciones durante la vista oral del juicio, cuando ya habían sido ejecutados los supuestos colaboradores y, por lo tanto, no necesitaba seguir encubriendo su supuesta relación con el grupo, admitió sus contactos con alguno de ellos, pero con posterioridad al atentado. Esta responsabilidad individual en el momento final de la acción fue admitida, de forma explícita, por el jurado que lo condenó a muerte, al tiempo que dejaba en libertad a individuos que le habían ayudado en su huida y hasta a aquellos que fueron condenados a cadena perpetua como cómplices de Pallás. En fin, esta interpretación individualista parece estar presente también en instancias superiores, como indica el acuerdo del Consejo de Ministros en el que se separaban los atentados de la Gran Vía y el del Liceo. Pero lejos de cualquier actuación reflexiva y moderada, el Estado español mostró su cara más represiva, reabrió el caso por el que ya había ejecutado al autor, y llevó al patíbulo a otras seis personas.

En tercer lugar, hay que señalar la más que posible utilización de los atentados para reprimir a aquellos que se oponían al régimen de la Restauración, con especial atención al movimiento obrero. No es extraño que un Estado que consideraba la lucha de los trabajadores contra el capital como opuesta a la moral pública —como señalaba la sentencia del Tribunal Supremo-, utilizara todos los medios a su alcance para su eliminación. Desde esta perspectiva y teniendo en cuenta la conmoción que el brutal atentado del Liceo causó en la opinión pública se puede entender que el número de detenidos tras el atentado del Liceo se contara por centenares. En las pesquisas que realizó la policía tras los dos atentados 
analizados aparecen, en primer lugar, los obreros que habían participado en las huelgas y manifestaciones del $1 .^{\circ}$ de mayo. Un ejemplo muy significativo es la noticia que recogía el Diario de Barcelona sobre Juan Bernich, acusado junto con Codina de mandar construir los artefactos, y del que se decía que había tomado parte activa en las huelgas de 1890. La información sobre Bernich ahondaba en su actuación durante los paros, en los que trató que los obreros de las fábricas de Barcelona no trabajaran, por lo que estuvo arrestado en las cárceles nacionales. Esta información se completaba con la reseña del envío por parte del Gobernador civil al Ministro de Gobernación de una copia de los informes y antecedentes de los 200 anarquistas detenidos últimamente ${ }^{85}$. Detenciones que podían alargarse por tiempo indefinido, y que mostraban la más que posible arbitrariedad del Estado. Como sucedió con un grupo de libertarios encarcelados a raíz del atentado contra Martínez Campos, el 24 de septiembre de 1893, y que el 17 de diciembre de 1894, es decir, más de un año después, continuaban en prisión sin que las autoridades tomaran ninguna decisión sobre su situación ${ }^{86}$. Es fácil imaginar los estragos que en la economía de una familia trabajadora de la época hacían este tipo de actuaciones, así como el aviso que llevaba implícito para aquellos que se implicaban en el movimiento obrero.

En definitiva, aunque a la hora de poner un ejemplo de la brutal represión ejercida por el Estado contra el anarquismo se ha tomado siempre como referencia el Proceso de Montjuich, la pauta de la actuación de las autoridades en este tipo de acciones se marcó con anterioridad, en concreto, a raíz del atentado del Liceo. La circunstancia de que tras el cruento atentado del Teatro, con la salvedad del intento de asesinato del Gobernador civil en enero de 1894, la capital catalana vivió una época de calma terrorista, pudo hacer pensar a las autoridades que las medidas adoptadas habían sido las adecuadas para acabar con las acciones anarquistas. Sin embargo, la persistencia en este tipo de represión tras el atentado de la procesión del Corpus, en 1896, demostró la gravedad del error.

85 Diario de Barcelona, 25 de enero de 1894.

86 El Corsario (La Coruña), 3 de enero de 1895. Los detenidos eran: Francisco Bartolomeu, José Molas, J. Guillamot, Pablo Bó, Matías Gabarró, Ramón Esteve, Ramón Ardiaca, José Artoneda, J. López, Francisco Regás, M. Alís, A. Saldani, Pedro Arolas, Antonio Llauradó, Antonio Mestre y S. Suñé. 